\title{
A SIGN IS WORTH A THOUSAND WORDS: JORDANIAN SHOP SIGNS IN VARIOUS LANGUAGES
}

\author{
Lana Qudeisat $^{(1) *}$ \& Luqman Rababah ${ }^{(2)}$ \\ School of Arts, Jadara University, Jordan ${ }^{(1)}$ \\ Associate Professor - School of Arts, Jadara University, Jordan ${ }^{(2)}$ \\ luqman@jadara.edu.jo
}

\begin{abstract}
Language is a powerful tool for communication in a variety of fields all around the world. People sometimes communicate in a variety of fields by combining the official language with languages used in other nations. Education, health, business, commerce, and other fields are among them. In Jordan, the commercial sector demonstrates the importance of the native tongue, as well as the diversity of languages used in store signage. This research looks on the languages used on commercial store signage in Irbid. According to the findings of this study, 36 percent of commercial store signs are monolingual English, which indicates that they are written entirely in English. Furthermore, 36\% of store signs are bilingual English - Arabic, meaning they are written in both English and Arabic. Other foreign languages, such as French, are written on $18 \%$ of store signs, whereas Arabic, the official language of Jordanians, is inscribed on $9 \%$. In conclusion, this study shows that English is widely utilized in the business sector in Irbid, as opposed to other foreign languages, which are infrequently used. It also highlights the strong use of English and Arabic, indicating that Irbid is a moderate and conservative city that values the use of the native tongue alongside English as a foreign language.
\end{abstract}

Key words: Linguistics Landscape, Shop Signs, Word formation, Semiotics. 


\section{Introduction}

Language is a powerful instrument that may be applied to a variety of situations. For example, languages are used in the economics, politics, education, health, advertising, and commerce to convey important features of each sector in order to achieve certain objectives (Guihang \& Bingjie, 2017). Foreign languages are extensively used in several domains and English language is one of the most significant foreign languages that is vastly used in the commercial field in countries all over the world where it is not an official language (Gerritsen et al., 2007; Piller, 2003). With respect to the use of foreign languages in Jordan, English language has spread beyond educational and social fields. It is surprising that English language is used and mixed into more fields whose incoming is ideal of the varieties of Arabic, essentially among members of wealthy classes (Alomoush \& Al-Na'imat, 2018). In addition, English language impacts opportunities and decisions which belong to the business field in Jordan. For example, in the commercial field shop owners have recourse to foreign languages and exclude their own mother tongue in order to show the highest degree of prestige (Obeidat, 2008). All foreign languages that are shown on signs of the commercial field have symbolic function which affect the situation of several languages compared to other spoken languages that reflect the social identity and power of the speakers (Landry \& Bourhis, 1997).

According to the number of foreign languages that people speak or use internationally, Arabic language represents one of the most substantial languages and it is the mother tongue of Jordanian people. In regards to the use of foreign languages in the field of department stores, owners of the shops have the desire to use foreign languages rather than Arabic in order to promote all services they introduce.

It has been said that the high desire of using English language in the process of promotion various products in the commercial field refers to the positive association that the buyer have with English and the positive associations indicate certain estimate for both the product and the language that is used (Gerritsen et al.2000; Kelly-Holmes, 2000;2005).

Additionally, languages that are used on signs can convey different messages about the strength, significance and relevance of the language in the society (Shohamy, 2006), that may have important inclusion for the existence of other foreign languages. Signs that are official such as traffic signs define the considerable and famous language or languages. While private signs such as commercial signs are much less under official control and indicate more languages than official ones do. Nevertheless, the disconnec- 
tion between the linguistic representation in official and private signs represents one of the considerable features of the linguistic landscape (Tan, 2014).

Research related to the appearance of foreign languages in the linguistic landscape of the shop signs indicates what is called multilingual worlds that reflect the variety of using foreign languages which maybe indicate the owner's attitudes, introduce a brief background about the shop and it identifies the actual linguistic features of these short texts (Bolton, 2012, p. 32). Moreover, the emergence and growth of multilingualism in many countries is due to several factors related to the state of migration, imperialism, federation, and border area of multilingualism (Fassold, 1984). Furthermore, in multilingual territories there is no official policy governing the presence of languages on public signs especially in private domains that tend to be forked (Shang \& Guo, 2017).

Shop signs have been studied from various perspectives that are related to their effects on marketing and brand promotion (Masai, 1972), the positive attitudes towards languages used on shop signs (Hussein et al., 2015) and the influence of the wide spread of English in shop signs around the world (Nikolaou, 2017; Mcarthur, 2000; Schlick, 2003; Griffin, 2004).

This study aims to explore the use of several languages on the commercial shop signs
Jadara Journal for Studies and Research Volume (seventh) for the year (2021)

in Irbid, the biggest city in the northern part of Jordan and to find out the linguistic features in texts used on shop signs to enrich the study of linguistic landscape in Jordan.

The "visibility and salience of languages on public and commercial signs" is referred to as the 'linguistic landscape (LL) (Landry \& Bourhis, 1997, p. 23). The frame of linguistic landscape of a specific area refers to "any sign or announcement located outside or inside a public institution or a private business in a given geographical location" (as cited in Ben-Rafael et al. 2006, p. 14). This presents an accurate and deep understanding of the frequent of all languages which are visible in the public sphere.

\section{Literature review}

In Jordanian cities, particularly in Irbid, the number of shop signs is increasing at an exponential rate. This occurrence, however, may reflect the diversity of languages used in shop signs, which, according to language specialists, may be investigated from many angles. LL is one of the important areas that studies the many linguistic characteristics found in the languages used on store signage (ALHyari \& Hamdan, 2019). Commercial shop signs, according to Al-Kharabseh (2008), impose a significant number of linguistic characteristics.

Linguistic landscape and shop signs

Landry and Bourhis (1997) define the lin- 
guistic landscape as "the language of public road signs, advertising billboards, street names, place names, commercial shop signs, and public signs on government buildings combines to form the LL of a given "territory” (p. 25). Landry and Bourhis (1997) explore the function of the language of public signboards by indicating the importance of the visibility and salience of languages with consideration to ethno linguistic rejuvenation. Spolsky (2009) adheres that the linguistic landscape is the use of languages in the public area and attracts the attention of passersby to understand "the multiliterate ecology of cities" (p. 23). Sign boards have been studied in the term of the different languages that are used in and the actual reflection and references of the used languages between usages and users. In addition, Cenoz \& Gorter (2006) indicate that the LL reflects the connection between societies and ethno linguistics.

The definition of Landry and Bourhis (1997) of the linguistic landscape is recently criticized by some researchers by indicating the limitation of the definition and expanding the new definition to involve various sets of literacy items including logos, icons, and images, in addition to languages presence in public spaces (Itagi \& Singh, 2002; Backhaus, 2007; Shohamy \& Gorter, 2009). Thus, the definition of LL becomes how the researchers determine the rules of linguistic landscape research based on data collection.

\section{Related studies}

According to David \& Manan (2015), they examined both the policy and strategies of languages used by the public of Petaling Jaya, in the state of Selangor, Malaysia. Also, they explore the patterns of languages especially those used on private and government signage. The researchers used two strategies in the process of analyzing the case of signage in the selected region. They collected 400 photos of signboards of restaurants, shops, offices and other cafe's then study them through theoretical premises and from the aspects of contrast and contradiction. The results of this study indicate that most of signboards in Petaling Jaya are bilingual or multilingual. Also, they find out that the users of signs respond to the official policy in regards to the national Bahasa Melaya (BM) regardless to the font size and language arrangement.

Shang \& Guo (2017) investigate the display of codes or languages that are used on shop signs in the neighborhood centers located in the Western part of Singapore that represent the largest and most populated one which inhibited by a million residents. He also explores the way of sitting out codes and languages on the shop signs. Moreover, he searched the actual factors that impact the choice of languages by business owners. They totally collected 1097 shop names 
appearing in neighborhood centers, only ten neighborhood centers were selected. They used a qualitative distribution measures to find out the explanation of the actual questions by emphasizing the relationship between the quantity of linguistic codes and the linguistic varieties in the used languages. They indicate that $96 \%$ of shop signs were written in English language but it is not considered as the most visually silent code especially when two or more codes are used or displayed. Chinese is the preferred code in both bilingual and multilingual signs which represent the main shop names. They asserted that there are various social factors which affect owner's choice of language such as the policy of the states macro language, demographic structure and ethnic and cultural identity.

Guihang \& Bingjie (2017) study languages employed in shop signs according to the shop owner's language choice in the capital city of Hubei province, Wuhan, especially in Han street in China in order to fertilize the field of linguist landscape in China. They also investigate the kinds of languages allocated in shop signs. Moreover, they explore the factors influencing language choices by shop owners. They collect photos of 147 commercial shops to analyze the language use in shop signs and provide functional explanations of different choices of language according to the shop owner's language choice that related to the commercial drive, English as LinguaFranca and the policy of Chinese languages. They use a qualitative measure to analyze languages in the form of database to keep it as a reference then they grouped the photos and coded them as a sheet in Excel.

According to the results of this study, the researchers find out that unilingual, bilingual and multilingual signs are not equally used by the shop owners, thus the first two kinds of signs take up nearly $100 \%$ of all shop signs but there is only one multilingualism sign which means that shop owners in Han streets prefer using both unilingual and bilingual signs rather than multilingual. They also indicated that despite the wide variety of languages used in the commercial shop signs, English language is the dominant one followed by Chinese and French.

Giyatmi, Hastuti \& Wijayava (2014) investigate how the English brand names in Indonesia are created. The population of the research includes all brand names written in English found in Indonesian products. Moreover, the samples of this study were chosen from three supermarkets in Solo which are Hypermart Gorro Assalam, Hypermart Grand Mall and Carefur. The collected data are analyzed by using a descriptive qualitative method. Furthermore, the researcher concludes that brand names in Indonesia can be formed by using various word formation 
processes including blending, affixation, compounding, acronyms, abbreviation, onomatopia and clipping.

\section{Gap of the study}

Although numerous research on shop signs have been done (Shang \& Gou, 2017), the majority of them were conducted in various languages (David \& Manan, 2015), distinct situations (ZHANG \& Tuo, 2015), and different techniques (Jing-Jing, 2015). (Guihang \& Bingjie, 2017). Thus, the purpose of this study is to fill a gap in the field of linguistic landscape by employing qualitative measures for all store signs in Irbid, Jordan, particularly shop signs at Irbid City Center, Jordan's largest mall. It will also contribute to the Jordanian literature.

Deniz and Lincoln (2000) opined that qualitative research approach is the most suitable approach definitely when the nature of the research problem's features is complex. In addition, qualitative research approach "offers greater latitude in selecting topics of interest" and these have made it an acceptable "form of research in many different academic and professional fields" (Yin, 2011, p. 6). According to Cresswell (2016), qualitative research uses an emergent design which indicates that the primary plan of a research cannot be specified and it accepts changeability even after the researcher inspect the field of study and collect data. For the purposes of the study, the researcher adopts a qualitative and quantitative approaches that fit the questions and give reasonable and acceptable answers for them. Cresswell (2013) described qualitative research as an approach that is used to examine, search and recognize all meanings that individuals or groups associate with a social or human problem. On the other hand, Denzin \& Lincoln (2000) pointed out that qualitative research comprises the study of natural settings for things, trying to make meaning of, or explain a specific phenomenon by identifying the meanings that people fetch to them. This approach mainly aims to give an appropriate answer of "how", "why" and "what" questions of a particular phenomenon (Green \& Thorogood, 2018). Moreover, this kind of method is the main and suitable one that the researcher relies on in the process of collecting data and samples. In addition, Eyisi (2016) stated that qualitative approach is useful because of several reasons. First, qualitative approach provides considerable data and details which reflect the reality and situation of people's life. Second, the data are regarded as being unique and supported, and third, qualitative approach examines the behavior and thought of individuals through a social situation and covers a large number of phenomena which is helpful to recognize and appreciate them thoroughly. Similarly, Yin (2011) asserted that qualitative research approach studies the conditions and meanings of human's lives and demonstrate the perspectives of people 
by giving many explanations through the contextual conditions that people live. Thus, the previous reasons present a justification of using mixed qualitative and quantitative approaches in this study.

This current study mainly aims to examine shop signs in Irbid city, Jordan by determining the languages used on shop signs in the commercial field and finding out the word formation processes of each one. Both qualitative and quantitative designs are used in this research, and the source of information and samples depends on statistical measures provided by a qualitative and quantitative approach. Data will be conducted in April, 2020 for the selected city which has huge commercial intensity.

\section{Methods}

The research includes all visual and textual store signs utilized in the commercial field in Irbid, particularly those written in several languages. Using the convenience sample, the researcher only chose commercial shop from one mall a, Irbid City Center Mall, which is Irbid's largest and most wellknown retail mall. It is situated in the city's heart. This study's sample includes a variety of shop signs from cafés, clothing and fashion stores, supermarkets, and a variety of eateries.
Table 3.1 Selected Numbers of Shop Signs in Each Floor

\begin{tabular}{cc}
\hline Floor Number & Number of shop signs \\
\hline F.1 & 25 \\
F. 2 & 50 \\
F. 3 & 45 \\
F. 4 & 30 \\
\hline
\end{tabular}

In terms of the first dimension, the researcher categorizes all languages used on store signs according to their prevalence. The researcher divides languages into categories such as Arabic, English, English - Arabic, and French. Furthermore, the researcher organizes varieties of languages in a table to determine the precise percentage of people who speak each language.

\section{Findings and discussion}

In this section, the questions of this study are answered and the objectives of this research are fulfilled. Therefore, the shop signs of Irbid City Center were investigated in order to identify the dimension of the language choice of the shop signs in Irbid city in Jordan. The total number of shop signs are 150 which analyzed qualitatively. To answer the first question, the collected languages from Ibid city center are ordered in Table (4.1) which reveals the most dominant languages. 
Table 4.1 Language choice: Number and Percentage of Shop Signs in Irbid City Center

\begin{tabular}{|c|c|c|}
\hline Language Choice & $\begin{array}{c}\text { Num- } \\
\text { ber of } \\
\text { signs }\end{array}$ & Percentage \\
\hline Arabic Language & 8 & $9 \%$ \\
\hline English Language & 32 & $36 \%$ \\
\hline English - Arabic & 32 & $36 \%$ \\
\hline Other Foreign Languages & 16 & $18 \%$ \\
\hline $\begin{array}{l}\text { Total } \\
88\end{array}$ & & \\
\hline
\end{tabular}

As mentioned earlier, the main aim of this research is to explore the extent of using languages on the commercial shop signs in Irbid. Table (4.1) shows that shop signs are divided into four categories. The categories of language choice are Arabic Language (9\%), English (36\%), English - Arabic (32\%), and other foreign languages (18\%). 62 shop signs are excluded of the total number of shop signs which are images, trade marks and names of financial institutions such as banks because most of them lack the variety of the used languages and others are proper nouns that belong to the person who invent the product or to the region where it is produced.

\section{Arabic Language}

Table (3.4) shows that the number of monolingual Arabic signs comprise only (9\%) percent of the total number of shop signs. The low percentage indicates that monolingual Arabic language is rarely used in Irbid City Center in Irbid city in Jordan. On the other hand, Arabic language is commonly used in other commercial streets in different cities in
Jordan. Al Hayari \& Hamdan (2019) clarify that the percentage of Arabic signs used in Prince Hamzih street and Al Hamam street in Salt around 88.6 percent. This proves that malls in Jordan are not considered one of the commercial places that preserve the use of Arabic language although it is the official language and the mother tongue of all Jordanian people (Hayari \& Hamdan, 2019). The following shop sign is written purely in Arabic language

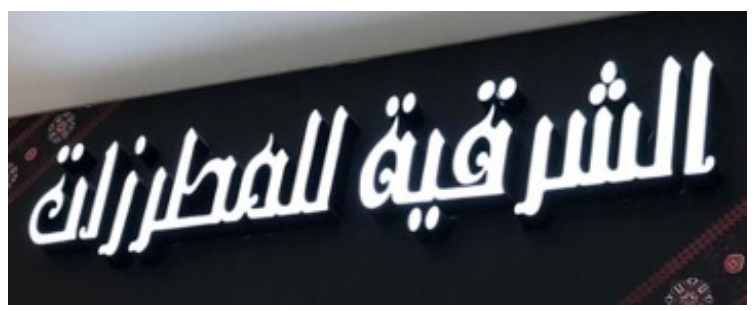

Fig 1. Monolingual Arabic clothes shop sign

\section{English Language}

In comparison to sign 1 "Monolingual Arabic Sign", sign 2 shows a monolingual English signs which comprise (36) percent of the selected signs. The percentage proves that most shop signs in Irbid City Center are written only in English. English is considered as the most common foreign language which is used in the commercial field precisely in malls. Amer and Obeidat (2014) reveal that English language is commonly used in Aqaba city in Jordan and emphasize that the high use of English reflects that English is one of the most important means which are used to attract the attention of tourists and ordinary citizens in the business and other commer- 
A SIGN IS WORTH A THOUSAND WORDS:

JORDANIAN SHOP SIGNS IN VARIOUS LANGUAGES

cial fields.

Fig 2. Monolingual English cosmetics sign En-

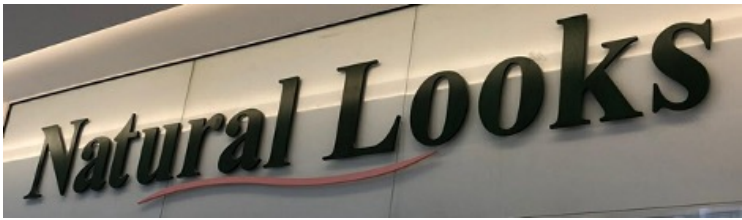

glish - Arabic

Using both languages English and Arabic in the commercial signs represents the most prevalent features of all selected shop signs. English - Arabic category comprises all shop signs that are written only with these two languages. English - Arabic shop signs constitute $(36 \%)$ the biggest number of the selected samples of shop signs. This percentage reflects the invasion of English language to the commercial field in Irbid. Amer \& oabeidat (2014) detect that bilingual English and Arabic shop signs are the highest percentage in Aqaba, Jordan 58.1\%. (Al Naimat, 2015; AlOmoush, 2015) point that it is unreasonable for Jordanian people to live without using bilingual Arabic and English language. The presence of both languages reflects the prominence of each one. Alomoush (2018) reveals that the value of using Arabic language represents a significant source of national strength and reflects the preservation of the mother language, while using English language is considered as a source of modernity, cultural awareness, prestige, attraction and open-mindedness.

Fig 3. Bilingual English - Arabic present sign
Jadara Journal for Studies and Research Volume (seventh) for the year (2021)

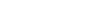

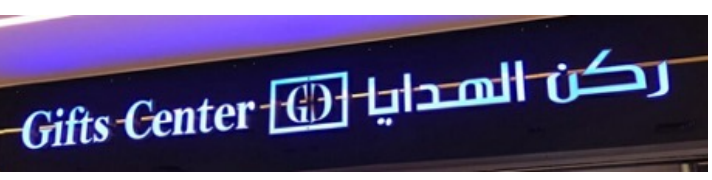

Other Foreign Languages

As table (3.4) shows, the percentage of using foreign languages in the commercial field in Irbid is $(18 \%)$ which indicates that foreign languages such as Turkish, Japanese, Italian, French and German are rarely used in comparison of using English language which is considered as the most visually displayed foreign language in Irbid City Center. The previous analysis indicates that the extent of using foreign languages is varied and not consistent. Mansour (2013) illustrates that the positive attitude toward foreign languages, the kinds of goods, the educational level of customers and the global impact of foreign cultures affect the choices of foreign languages in shop signs. The following sign is written in Turkish language which is one of foreign languages used in the commercial field in Jordan

Fig 4. Foreign language brand clothes sign

According to the previous analysis, the researcher finds out that monolingual Arabic

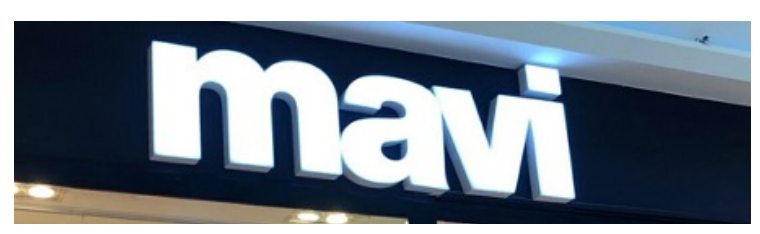

language, monolingual English, bilingual English-Arabic, and other foreign languages are not equally used which demonstrates the 
linguistic diversity in Irbid. Moreover, bilingual English-Arabic and monolingual English are the most vibrant languages in the commercial field in comparison to monolingual Arabic and other foreign languages. Additionally, English is the master language that is highly used in the commercial field in Irbid comparing to other foreign languages that occupy minor importance. This result comes consistent with what Guihang\&Bingjie (2017) investigated with regards to the kinds of languages allocated in shop signs in the capital city of Hubei province in Han street in China.

\section{Conclusion and recommendations}

By exploring the extent of using languages in shop signs and by analyzing the word formation processes in these shop signs, the researcher has come with the following conclusions.

1. This study indicated that English language is highly used in the commercial field in comparison to other foreign languages that are rarely used. It should be stated that $36 \%$ of the signs were monolingual English language and this is a surprising one since Arabic is the mother tongue for Jordanian people. This means that English as a foreign language can be used in other fields to achieve several goals including tourism and academic domains and this needs more efforts to shed light on the importance of using other foreign languages alongside the native language.

2. It was pointed in this study that bilingual English - Arabic languages which are highly used in the commercial shop signs in malls in Irbid city. It should be mentioned that $36 \%$ of these signs were written by using both languages (English and Arabic). This revealed that Jordanian people maintain the official language alongside with English language and detected that Irbid city is still using both languages.

Because the present study's sample was confined to a single mall in Irbid, further research is needed to explore store signage at malls across Jordan, including in the capital city of Amman. Also, the same research may be repeated over a long length of time to see if the status of utilizing languages has remained the same or has changed. Because this study shows that English as a foreign language is widely utilized in commercial shop signage in Irbid city center, a similar study should be conducted in other shops and businesses on public roadways in Jordan's northern regions. 
A SIGN IS WORTH A THOUSAND WORDS:

JORDANIAN SHOP SIGNS IN VARIOUS LANGUAGES

\section{References}

ALHyari, D. A., \& Hamdan, J. M. (2019).

A Linguistic Study of Shop Signs in Salt, Jordan. Journal of Language Teaching and Research, 10(5), 937-953.

Al-Kharabsheh, A., Al-Azzam, B., \& Obeidat, M. (2008). Lost in translation: shop signs in Jordan. Meta: journal des traducteurs/Meta: Translators' Journal, 53(3), 717727.

Alomoush, O. I. S., \& Al-Na'imat, G. K. (2018). English as the lingua Franca in visual touristic Jordan: the case of Petra. International Journal of Applied Linguistics and English Literature, 7(4), 1-13.

Ben-Rafael, E., Shohamy, E., Hasan Amara, M., \& Trumper-Hecht, N. (2006). Linguistic landscape as symbolic construction of the public space: The case of Israel. International journal of multilingualism, 3(1), 7-30.

Ben-Rafael, E., ～\& Ben-Rafael, M. (2015). Linguistic landscapes in an era of multiple globalisations. Linguistic Landscape, 1, 19-37. doi: 10.1075/11.1.1-2.

David, M. K., \& Manan, S. A. (2015). Language ideology and the linguistic landscape: A study in Petaling Jaya, Selangor, Malaysia. Linguistics \& The Human Sciences, 11(1), 51-66.

Fasold, R. (1984). The Sociolinguistics of Society, Wiley-Blackwell, England.
Jadara Journal for Studies and Research Volume (seventh) for the year (2021)

Gerritsen, M.; Nickerson, C.; van Hooft, A.; van Meurs, F.; Nederstigt, U.; Starren, S. and Crijns, R. (2007), "English in Product Advertisements in Belgium, France, Germany, the Netherlands and Spain," in: World Englishes, Vol. 26 (3), 291-315.

Giyatmi, G., Hastuti, E. D., Wijayava, R., \& Arumi, S. (2014). The Analysis of English Word Formations Used on Brand Names Found in Indonesian Products. Register Journal, 7(2), 179-204.

Gorter, D. (2006). Introduction: The study of the linguistic landscape as a new approach to

Green, J., \& Thorogood, N. (2018). Qualitative methods for health research. sage.Griffin, 2004

Guihang, G. U. O., \& Bingjie, L. I. (2017). Linguistic landscape of China: A case study of the language use of shop signs in Wuhan. Studies in Literature and Language, 15(1), 1-9.

Hussein, R. F., Nofal, M. Y., \& Mansour, A. J. (2015). The language of shop signs in Amman: A sociolinguistic study. International Journal of Educational Research and Reviews, 3(2), 155164.

Itagi, N. H., \& Singh, S. K. (2002) Introduction. In: Itagi, N. H. \& Singh, S. K. eds., Linguistic landscaping in India with particular reference to the new states: TOP-DOWN AND BOTTOM-UP LINGUISTIC proceedings of a seminar. Mysore: Central Institute of Indian Languages and Mahatma Ganhi International Hindi 
University, pp. ix-xii.

Kelly-Holmes, H. (2000). Bier, parfum, kaas: Language fetish in European advertising. European Journal of Cultural Studies, 3(1), 67-82.

Landry, R., \& Bourhis, R. Y. (1997). Linguistic landscape and ethnolinguistic vitality: An empirical study. Journal of language and social psychology, 16(1), 23-49.

McArthur, T. (2000, January). Interanto: The global language of signs. English Today 61, Vol. $16(1), 33-43$

multilingualism. International Journal of Multilingualism, 3(1), 1-6.

Nikolaou, A. (2017). Mapping the linguistic landscape of Athens: The case of shop signs. International Journal of Multilingualism, 14(2), 160-182.

Nikolaou, A., \& Shah, S. (2019). Linguistic Landscape in Swat, Pakistan: A Survey of Shop Signs. Kashmir Journal of Language Research, 22(2).

Obeidat, M. (2008). Lost in Translation: Shop Signs in Jordan. Meta: Translators' Journal. Er- udit, pp. 717-727.

Piller, I. (2003), “Advertising as a Site of Language Contact," in: Annual Review of Applied Linguistics, Vol. 23, 170-183.

Schlick, M. (2003). The English of shop signs in Europe. English Today, 19(1),3.;

Shang, G., \& Guo, L. (2017). Linguistic landscape in Singapore: What shop names reveal about Singapore's multilingualism. International Journal of Multilingualism, 14(2), 183-201. Shohamy, E. (2006). Language policy: Hidden agendas and new approaches. Routledge.

Shohamy, E., \& Gorter, D. (Eds.). (2008). Linguistic landscape: Expanding the scenery. Routledge.

Spolsky, B. (2009). Language management. Cambridge University Press.

Yin, R. K. (2011). Qualitative research from start to finish. New York: Guilford Press.

Zhang, B., \& Tuo, X. U. (2015). English translation of linguistic signs: A study from the perspective of linguistic landscape. Studies in Literature and Language, 11(3), 35-42. 